\title{
Purification and identification of $\beta$-casein phosphopeptide (1-25)
}

\author{
Muhammad Ali Naqvi, Jasjit Singh, Eugene Han, Koushan Farshad, and Dérick Rousseau ${ }^{1}$ \\ Department of Chemistry and Biology, Ryerson University, Toronto, Ontario, Canada, M5B 2K3
}

\begin{abstract}
The $\beta$-casein phosphopeptide $1-25(\beta \mathrm{CPP})$ is involved in calcium binding, cellular transduction, and dental remineralization. The objective of this work was to improve upon the original protocol commonly used for isolation of this phosphopeptide from $\beta$-casein. This method exploits the isoelectric point of $\beta$-casein fragments to selectively precipitate $\beta \mathrm{CPP}$. The highest $\beta \mathrm{CPP}$ extraction yield reported to date with this protocol is $14.4 \pm 0.5 \%$ of theoretically available $\beta \mathrm{CPP}$. The present work optimizes 2 steps in this procedure, namely the length of trypsin digestion and incorporation of cold acetone precipitation, to increase the yield to $32.3 \pm 5.4 \%$. Reverse-phase HPLC indicated high purity of the isolate, whereas mass spectrometry confirmed 2 forms of the phosphopeptide: fragments 1-25 $(87 \%)$ and $2-25(13 \%)$. The adaptation of the existing protocol represents a significant improvement in extraction yield and facilitates preparation of larger amounts of high-purity $\beta \mathrm{CPP}$ for subsequent analysis and use in functional foods and other applications.
\end{abstract}

Key words: casein, phosphopeptide, isolation, HPLC, mass spectrometry

\section{INTRODUCTION}

Casein phosphopeptides are obtained through tryptic digestion of the milk proteins $\alpha_{\mathrm{S}^{-}}, \alpha_{\mathrm{S}^{-}}$, and $\beta-\mathrm{CN}$ (Cross et al., 2007). Given their capacity to improve calcium bioavailability, they have been shown to mitigate dental caries as well as oral diseases by hindering biofilm formation and favoring nucleation of apatitic $\mathrm{CaHPO}_{4}$ (Cross et al., 2005, 2007). Their binding properties (Little and Holt, 2004) and resilience against proteolysis (Boutrou et al., 2010) support their function as calcium carriers (Cosentino et al., 2010).

The $\beta$-casein phosphopeptide ( $\boldsymbol{\beta C P P}$ ) fragment [RELEELNVPGEIVE $\Sigma L \Sigma \Sigma \Sigma E E S I T R$ ] extends 25 AA from the $\mathrm{N}$ terminus of $\beta-\mathrm{CN}$ (Farrell et al., 2002). It

\footnotetext{
Received February 9, 2016.

Accepted June 30, 2016

${ }^{1}$ Corresponding author: rousseau@ryerson.ca
}

contains 4 negatively charged phosphorylated serines $(\Sigma)$ that sequester calcium ions and promote the formation of calcium phosphate $\left(\mathrm{CaHPO}_{4}\right)$ nanoclusters (Little and Holt, 2004). Once formed, this peptide-mineral complex becomes an effective vehicle for calcium transport (Holt et al., 1996; Smyth et al., 2004).

The theoretical proportion of $\beta \mathrm{CPP}$ present in $\beta-\mathrm{CN}$ is $\sim 13 \%$ (wt/wt; Supplemental Data, http://dx.doi. org $/ 10.3168 /$ jds.2016-11010). The scientific literature shows that 2 methods currently exist to isolate $\beta C P P$. One is based on sodium caseinate (Reynolds et al., 1994) whereas the other requires pure $\beta-\mathrm{CN}$ as the starting material, with the latter seeing more extensive use (Peterson et al., 1958; Manson and Annan, 1971); the latter method has been shown to yield an extraction efficiency of $\sim 14 \%$.

The goal of the present work was to improve upon the method of Manson and Annan (1971) by optimizing 2 extractions steps, namely the length of trypsin digestion as well as the incorporation of cold acetone precipitation. Optimizing the length of trypsin digestion ensured the maximum extraction of the desired peptide whereas the use of cold acetone decreased the solubilization of $\beta \mathrm{CPP}$, thus resulting in an increase in yield. Overall, an increase in extraction yield to $\sim 32 \%$ of theoretically available $\beta \mathrm{CPP}$ was obtained.

\section{MATERIALS AND METHODS}

\section{Isolation of $\beta C P P$}

Extraction. $\beta$-Casein was extracted from sodium caseinate (Sigma-Aldrich, Oakville, ON, Canada) using the method of Post et al. (2009). A mass of $4.4 \mathrm{~g}$ of $\beta-\mathrm{CN}$ was dissolved in $214 \mathrm{~mL}$ of reverse-osmosis (RO) water, following the starting conditions used by Manson and Annan (1971). The theoretical yield of $\beta \mathrm{CPP}$ expected from this amount of $\beta$-CN was $572 \mathrm{mg}$ relative to the starting weight of $\beta-\mathrm{CN}$ (Supplemental Data, http://dx.doi.org/10.3168/jds.2016-11010). The solution $\mathrm{pH}$ was adjusted to 8.60 using $1 \mathrm{M} \mathrm{NaOH}$, which was optimum for $\beta$-CN digestion. In an ideal situation, $\beta-\mathrm{CN}$ should be completely digested to final yield of the isolated peptide. Therefore, trypsin digestion $(20 \mathrm{mg}$ of 
trypsin in $4 \mathrm{~mL}$ of $0.001 \mathrm{M} \mathrm{HCl}$ ) was performed for 50 min, $2 \mathrm{~h}$, and $16 \mathrm{~h}$ at $25^{\circ} \mathrm{C}$, with the digestion followed via a $\mathrm{pH}$ meter. Once complete, the $\mathrm{pH}$ of the solution was adjusted to 4.7 with $1 \mathrm{M} \mathrm{HCl}$ to precipitate unreacted $\beta-\mathrm{CN}$, which was then removed by centrifugation $\left(3,000 \times g\right.$ for $10 \mathrm{~min}$ at $\left.25^{\circ} \mathrm{C}\right)$. The supernatant was exposed to $53.5 \mathrm{~mL}$ of $10 \%$ (wt/wt) $\mathrm{BaCl}_{2}$ and 133.75 $\mathrm{mL}$ of denatured ethanol (Fisher Scientific, Waltham, MA). The crude phosphopeptide was isolated by centrifugation at $3,000 \times g$ for $10 \mathrm{~min}$ at $25^{\circ} \mathrm{C}$.

Purification. The crude phosphopeptide was dissolved in $25 \mathrm{~mL}$ of $\mathrm{RO}$ water and the $\mathrm{pH}$ of the solution was decreased to 3.5 using $0.1 \mathrm{M} \mathrm{HCl}$. Addition of acetone allows precipitation of peptides or proteins. Enthalpy of solution for hydrophilic peptides or proteins is positive, so decreasing the temperature of acetone to $-20^{\circ} \mathrm{C}$ is likely to increase precipitation and, ultimately, yield. A volume of cold acetone $\left(-20^{\circ} \mathrm{C}\right)$ equivalent to 4 times the sample volume was added slowly with constant stirring to the solution. The precipitate formed was removed by centrifugation $(3,000 \times g$ for $10 \mathrm{~min}$ at $25^{\circ} \mathrm{C}$ ), dissolved in $15 \mathrm{~mL}$ of $\mathrm{RO}$ water, and the $\mathrm{pH}$ was reduced to 2.0 using $1 \mathrm{M} \mathrm{HCl}$. The precipitate was removed by centrifugation $(3,000 \times g$ for $10 \mathrm{~min}$ at $25^{\circ} \mathrm{C}$ ) and the $\mathrm{pH}$ of the supernatant was increased to 3.5 using $1 \mathrm{M} \mathrm{NaOH}$. The cold acetone purification step was repeated. All extractions were performed in triplicate. The extraction yields were compared with the original method of Manson and Annan (1971; Table 1).

\section{Chromatographic Identification of $\beta-C N$ and Sodium Caseinate}

Approximately $10 \mathrm{mg}$ of $\beta$-CN and sodium caseinate were dissolved separately in buffer containing $6 \mathrm{M}$ guanidine hydrochloride, $0.02 M$ 1,4-dithioerythritol, and $0.005 M$ sodium citrate (Sigma-Aldrich). The HPLC was performed using a PLRP-S reversed phase (RP) analytical column $(150 \times 4.6 \mathrm{~mm})$ with $300 \AA$ pore diameter and $5 \mu \mathrm{m}$ particle size (Polymer Laborato- ries, Church Stretton, Shropshire, UK). The column was installed in an Agilent Series 1260 Infinity HPLC system (Agilent, Mississauga, ON, Canada). The 2 mobile phases were solvent A $[1 \%$ (wt/wt) acetonitrile and $0.1 \%$ (wt/wt) trifluoroacetic acid (TFA) in deionized water] and solvent B [1\% (wt/wt) deionized water and $0.1 \%$ (wt/wt) TFA in acetonitrile]. The gradient eluted from 24 to $46 \%$ solvent B in 24 min, then to $95 \%$ within $5 \mathrm{~min}$ and then was kept constant for $5 \mathrm{~min}$. The flow rate was held constant at $0.8 \mathrm{~mL} / \mathrm{min}$ and the temperature of the column was $45^{\circ} \mathrm{C}$. Absorbance detection was performed at $220 \mathrm{~nm}$.

\section{Identification of $\beta C P P$ by RP-HPLC}

Ten milligrams of $\beta \mathrm{CPP}$ was dissolved in $2 \mathrm{~mL}$ of an aqueous solution of $0.1 \%$ ( $\mathrm{vol} / \mathrm{vol})$ TFA. Twenty-five microliters of this sample was analyzed by RP-HPLC using the PLRP-S reversed phase analytical column, as above. The mobile phases were solvent A [1\% (wt/ wt) acetonitrile and $0.1 \%$ (wt/wt) TFA in deionized water $]$ and solvent B [0.1\% (wt/wt) TFA and $60 \%$ (wt/ wt) acetonitrile in deionized water]. A linear solvent gradient at a constant flow rate of $0.8 \mathrm{~mL} / \mathrm{min}$ eluted from 0 to $80 \%$ solvent B in $60 \mathrm{~min}$.

\section{Identification of $\beta C P P$ by MS}

Peptide solutions were prepared in $100 \mathrm{~m} M$ ammonium formate buffer ( $\mathrm{pH}$ 7.5). All data were collected on a microTOF II electrospray-ionization time-of-flight mass spectrometer (ESI-MS; Bruker Daltonics, Milton, ON, Canada) in negative ion mode. Sodium iodide was used as the mass calibrant. The scan conditions for the ESI-MS were end plate offset, $-500 \mathrm{~V}$; capillary, $420 \mathrm{~V}$; nebulizer, $1.97 \mathrm{~atm}$; dry gas flow, $8.0 \mathrm{~L} / \mathrm{min}$; dry temperature, $80^{\circ} \mathrm{C}$; capillary exit, $180 \mathrm{~V}$; skimmer 1, $50.0 \mathrm{~V}$; hexapole $1,23.0 \mathrm{~V}$; hexapole radio frequency, $600 \mathrm{~V}$; skimmer 2, $22.0 \mathrm{~V}$; lens 1 transfer, $88.0 \mu \mathrm{s}$; lens 1 prepulse storage, $23.0 \mu \mathrm{s}$. The range used was 50 to

Table 1. Comparison of the original and the optimized method for isolating $\beta$-casein phosphopeptide $1-25$ ( $\beta$ CPP; starting amount of $\beta$-CN $=4.4 \mathrm{~g})^{1}$

\begin{tabular}{|c|c|c|}
\hline No. & Original method (Manson and Annan, 1971) & Optimized method (present study) \\
\hline 1 & Trypsin digestion of $\beta-\mathrm{CN} ; \mathrm{pH} 8.05,50 \mathrm{~min}$ & Trypsin digestion of $\beta$-CN; $\mathbf{p H} \mathbf{8 . 6 0 ,} \mathbf{2} \mathbf{h}$ \\
\hline 2 & $\mathrm{pH}$ adjusted to 4.7 ; supernatant kept & $\mathrm{pH}$ adjusted to 4.7 ; supernatant kept \\
\hline 3 & $\begin{array}{l}0.25 \% \text { (vol/vol) } \mathrm{BaCl}_{2} \text { and } 50 \% \text { (vol/vol) ethanol added; } \\
\text { precipitate kept }\end{array}$ & $\begin{array}{l}0.25 \% \text { (vol/vol) } \mathrm{BaCl}_{2} \text { and } 50 \% \text { (vol/vol) of ethanol added; } \\
\text { precipitate kept }\end{array}$ \\
\hline 4 & $\mathrm{pH}$ adjusted to 3.5 ; acetone added; precipitate kept & $\mathrm{pH}$ adjusted to 3.5 ; cold acetone added; precipitate kept \\
\hline 5 & $\mathrm{pH}$ adjusted to 2.0 ; supernatant kept & $\mathrm{pH}$ adjusted to 2.0 ; supernatant kept \\
\hline 6 & pH adjusted to 3.5 ; acetone added; precipitate kept & pH adjusted to 3.5 ; cold acetone added; precipitate kept \\
\hline & Percent yield: $14.4 \pm 0.5 \%$ & Percent yield: $32.3 \pm 5.4 \%$ \\
\hline
\end{tabular}

\footnotetext{
${ }^{1}$ Samples were dried for $24 \mathrm{~h}$. Changes are shown in bold.
} 
$3,000 \mathrm{~m} / z$, averaging $2 \times 0.5 \mathrm{~Hz}$. Spectra were constructed and deconvoluted using the Bruker Compass Data Analysis 4.0 software package (Bruker Daltronics).

\section{RESULTS AND DISCUSSION}

Table 1 outlines the modifications made to the original extraction protocol of Manson and Annan (1971). The theoretical proportion of $\beta \mathrm{CPP}$ present in $\beta$-CN is $\sim 13 \%$ (wt/wt; Supplemental Data; http://dx.doi. org/10.3168/jds.2016-11010). Replication of the existing method (Peterson et al., 1958; Manson and Annan, 1971 ) yielded an extraction efficiency of $\sim 14 \%$, whereas the present improvements increased the extraction yield to $\sim 32 \%$ of theoretically available $\beta \mathrm{CPP}$ (Table $1)$. Two steps in this procedure were modified, namely the length of trypsin digestion, which was increased to $2 \mathrm{~h}$ at a slightly higher $\mathrm{pH}$ to optimize digestion (step 1 ), and use of cold acetone precipitation (steps 4 and $6)$; the other steps were not modified.

Acetone is often used for protein precipitation as it reduces the dielectric constant of the solution and can disrupt the hydration layer around proteins (Arakawa and Timasheff, 1985). The increase in peptide precipitation at $-20^{\circ} \mathrm{C}$ indicated that its solubility was lower at this temperature. For molecules with solubility proportional to temperature, the enthalpy $(\Delta H)$ of solubilization is positive and the reaction is endothermic (Pertzoff, 1933). Although solubility data for $\beta \mathrm{CPP}$ have not been reported, comparison with glutamic acid (a reasonable proxy given that there are 7 in $\beta \mathrm{CPP}$ ) shows that its solubility is proportional to temperature in both water and acetone (Pertzoff, 1933). The use of cold acetone improved precipitation of $\beta \mathrm{CPP}$ (Supplemental Table S1; http://dx.doi.org/10.3168/ jds.2016-11010).

Figure 1 shows the chromatograms of sodium caseinate and purified $\beta-\mathrm{CN}$. The peak labels are in accordance with those of Post et al. (2009). The chromatogram of sodium caseinate shows peaks for $\kappa^{-}, \alpha_{\mathrm{S}^{-}}, \alpha_{\mathrm{S}^{-}}$, and $\beta-\mathrm{CN}$ at 10.0 to $12.5,12.5$ to 15,17 to 20 , and 20 to $24 \mathrm{~min}$, respectively, with the former 3 absent from purified $\beta$-CN. Differences in peak height are due to minor variations in HPLC sample concentrations.

Subsequent digestion of $\beta$-CN using trypsin resulted in the cleavage of the peptide bonds between the acidic carboxyl and the amine group along the protein backbone (Rawlings and Barrett, 1994). Tryptic digestion of $\beta$-CN showed an initial drop of $0.6 \mathrm{pH}$ units within the first min due to the presence of $\mathrm{HCl}$ in the trypsin solution. According to Manson and Annan (1971), the reaction should be complete within $50 \mathrm{~min}$; however, when accounting for the $\mathrm{pH}$ drop due to $\mathrm{HCl}$ at $50 \mathrm{~min}$, the digestion was only $93 \%$ complete (Supplemental Table S2; http://dx.doi.org/10.3168/jds.2016-11010). At this point, $\sim 300 \mathrm{mg}$ of residual $\beta$-CN was left unreacted from the starting amount of $4.4 \mathrm{~g}$ (Supplemental Table S2). After $2 \mathrm{~h}$, the reaction was $97 \%$ complete, which permitted another $176 \mathrm{mg}$ of $\beta-\mathrm{CN}$ to be digested, theoretically yielding an increase of $23 \mathrm{mg}$ in $\beta C P P$. Experimentally, this increase in digestion time increased $\beta \mathrm{CPP}$ yield by $22 \mathrm{mg}$. Given the agreement between the theoretical and observed results, the model shown in Figure 2 may be used to control the extent of digestion with high accuracy under these experimental conditions.

Reverse-phase HPLC was used to identify and quantify $\beta \mathrm{CPP}$ and other peptides generated during $\beta-\mathrm{CN}$ digestion. Figure 3 shows chromatograms corresponding to purified $\beta \mathrm{CPP}(\mathrm{A})$ and trypsin digestion times of casein of $50 \mathrm{~min}(\mathrm{~B}), 2 \mathrm{~h}(\mathrm{C})$, and $16 \mathrm{~h}(\mathrm{D})$, where the arrow in each chromatogram marks the peak corresponding to $\beta \mathrm{CPP}$. The peptide eluted at $\sim 32 \mathrm{~min}$ and increased in height with digestion time. In addition, the $\beta$-CN peak at $\sim 51$ min disappeared following $16 \mathrm{~h}$ of digestion (Figure 3 ). It was expected that increasing $\beta$-CN digestion time would also increase the yield of the purified phosphopeptide; however, extending the diges-

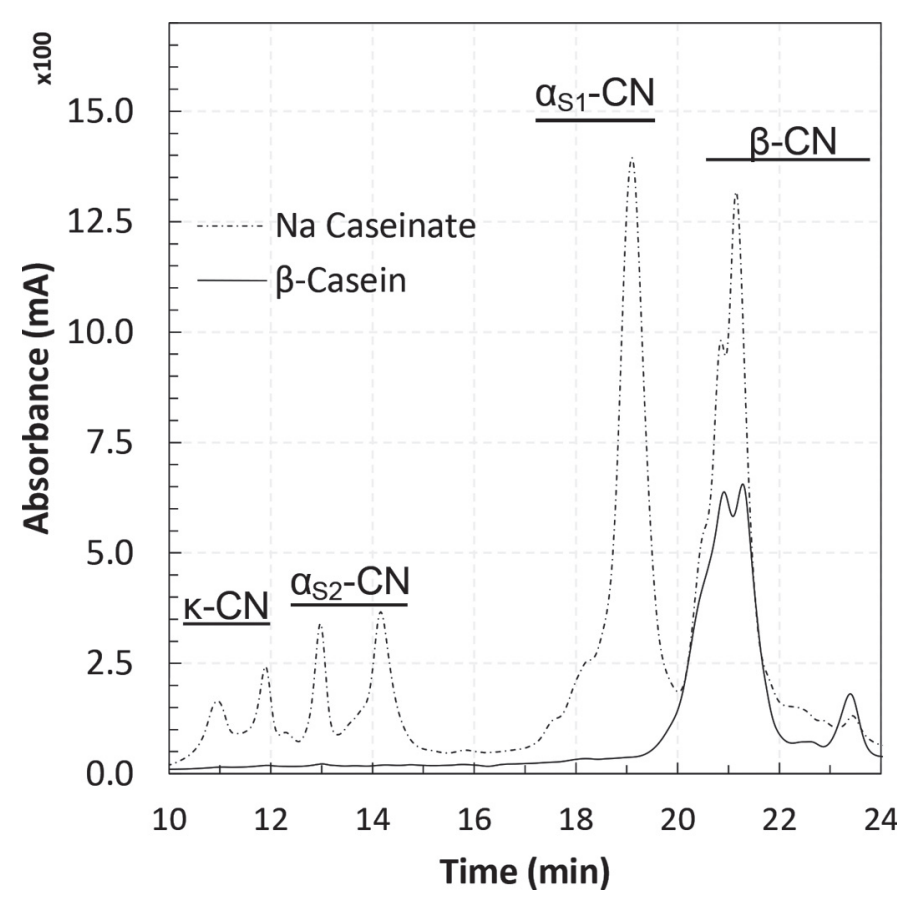

Figure 1. An HPLC chromatogram of sodium caseinate and purified $\beta$-CN; absorbance was recorded at $220 \mathrm{~nm}$. This chromatogram shows that other caseins in the isolate do not compromise purity of $\beta-\mathrm{CN}$. 


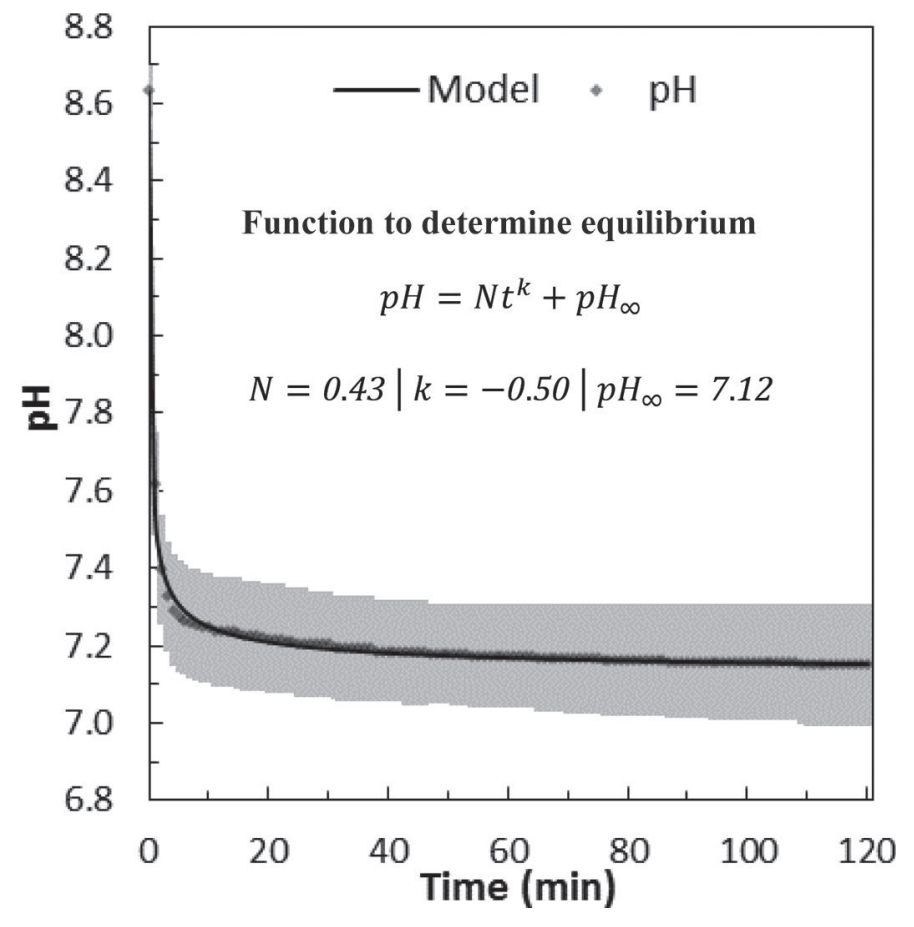

Figure 2. Change in $\mathrm{pH}$ during the digestion of $\beta-\mathrm{CN}$ via trypsin. The $\mathrm{pH}$ decreases due to hydrolysis of the peptide bond over time, which allows the monitoring of trypsin digestion. In the equation above, $N$ is the scaling constant, $t$ is time, and $k$ is the power of $\mathrm{pH}$ decay.

tion time decreased extraction yield from a maximum of 32 to $25 \%$. Such degradation was likely due to the continued exposure to the enzymatic solution. It has been shown that the $\mathrm{N}$ terminus 1-25 peptide fragment of $\beta-\mathrm{CN}$ is resilient against proteolysis given its 4 phosphorylated serines that sterically hinder enzymatic cleavage of the amide bonds (Benore-Parsons et al., 1989). Though this steric hindrance may reduce the degradation, extended exposure to peptidases such as trypsin can eventually lead to degradation of $\beta \mathrm{CPP}$ (Boutrou et al., 2010).

The appearance of one peak for $\beta \mathrm{CPP}$ in Figure 3 suggested presence of one form of the phosphopeptide or perhaps highly chemically similar species. According to Tan et al. (1993), 2 forms of the peptide elute within the single peak, the $\mathrm{N}$ terminus $1-25$ and 2-25 fragments of $\beta-\mathrm{CN}$ (Tan et al., 1993). The identity of the purified phosphopeptide was confirmed by ESI-MS. The ESI mass spectra typically contain similar species of the analyte in different charge states (Supplemental Figure S1; http://dx.doi.org/10.3168/jds.2016-11010). Therefore, the $\beta \mathrm{CPP}$ spectrum was deconvoluted with a grouping window of $0.05 \mathrm{~m} / z$ so that all multiplecharge species could be recalculated into a single charge group $(z=-1)$. Based on the AA sequence of $\beta-\mathrm{CN}$
(Supplemental Table S2; http://dx.doi.org/10.3168/ jds.2016-11010), we noted 2 fragments of the phosphopeptide: (1) AA 1-25 (molecular weight $=3,122 \mathrm{Da}$ ) and (2) AA 2-25 (molecular weight $=2,966 \mathrm{Da}$ ). Peak b in the ESI-MS spectrum at $3,122.2 \mathrm{~m} / z$ corresponded to the 1-25 phosphopeptide sequence, and peak a at 2,966 $\mathrm{m} / z$ was the 2-25 phosphopeptide (Figure 4; Supplemental Table S2). The relative peak heights indicated that the pure extract contained $87 \%$ of the 1-25 fragment and $13 \%$ of the $2-25$ form of the phosphopeptide (Supplemental Table S1; http://dx.doi.org/10.3168/ jds.2016-11010). In addition, 2 peaks preceding peak $\mathrm{b}$ at locations of $3,258.2$ and $3,393.1 \mathrm{~m} / z$ were labeled as peaks $\mathrm{c}$ and $\mathrm{d}$, respectively. The regular distance between peaks b, c, and d, corresponding to a mass of $137.3 \mathrm{~m} / \mathrm{z}$, was equal to the mass of barium used during step 3 (Table 1). It was assumed that reducing the $\mathrm{pH}$ should make the barium salt of the peptide susceptible to dissociation. However, the reduction in $\mathrm{pH}$ to 3.5 and subsequent precipitation using cold acetone did not completely remove it. The remaining peaks in Figure 4 are derivatives with barium and sodium ions bound to $\beta C P P$.

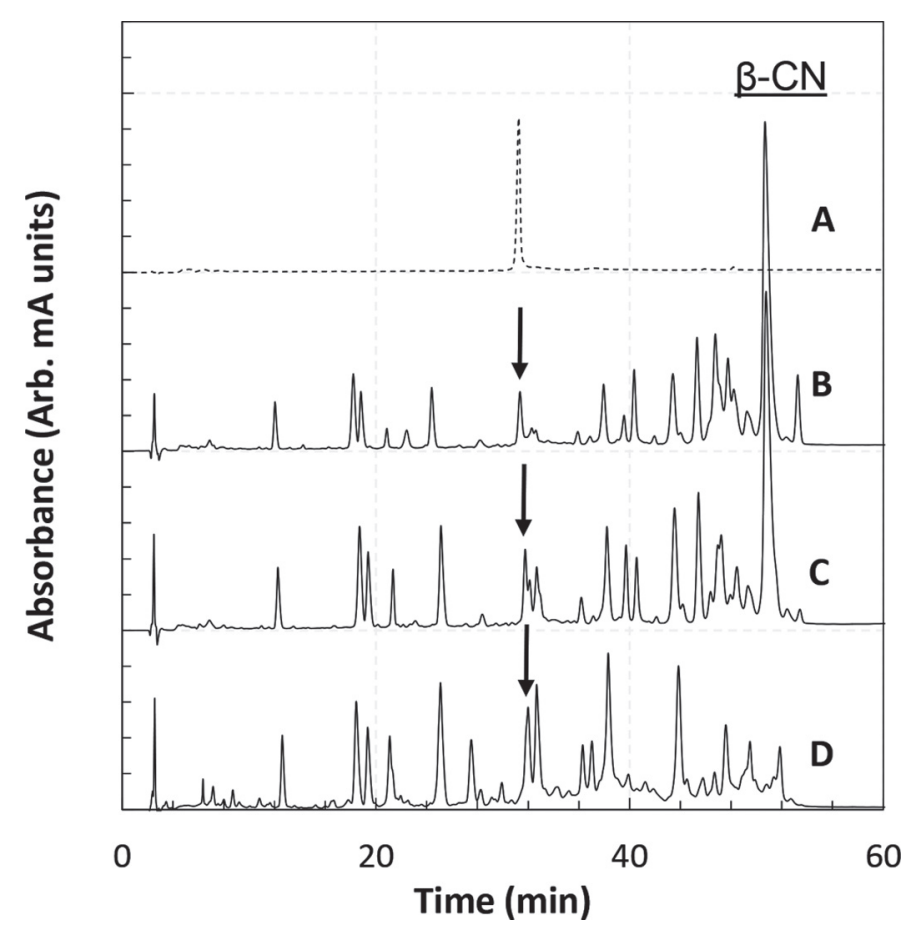

Figure 3. Comparative chromatograms of purified $\beta$-casein phosphopeptide 1-25 ( $\beta \mathrm{CPP}$ ) sample (A) and of the tryptic digest after 50 min (B), $2 \mathrm{~h}(\mathrm{C})$, and $16 \mathrm{~h}(\mathrm{D})$ of reaction. The large peak of $\beta$-CN appears at $51 \mathrm{~min}$ and the peptide $\beta \mathrm{CPP}$ appears at $32 \mathrm{~min}$; the arrow in each chromatogram marks the peak corresponding to $\beta \mathrm{CPP}$. This chromatogram shows the effect of digestion time on the quantity of parent protein $\beta-\mathrm{CN}$ and the generated peptide $\beta \mathrm{CPP}$. 


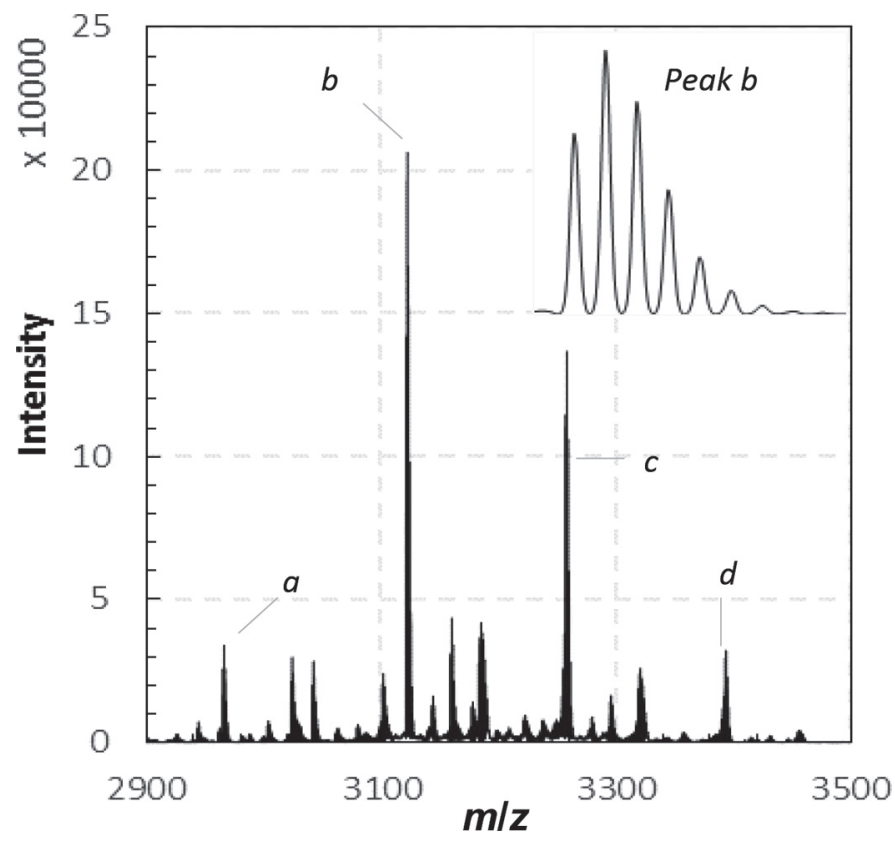

Figure 4. Deconvoluted electrospray-ionization time-of-flight mass spectrum of purified $\beta$-CN phosphopeptide. Peak a corresponds to $2,966 \mathrm{~m} / z$, which relates to $\beta$-casein phosphopeptide ( $\beta \mathrm{CPP} ; 2-25)$. Peak b, observed at $3,122.2 \mathrm{~m} / z$, corresponds to $\beta \mathrm{CPP}(1-25)$. The inset shows the magnified view of peak $\mathrm{b}$ from 3,120 to $3,130 \mathrm{~m} / z$. Peaks b, c, and d are separated by $137.3 \mathrm{~m} / z$, which is the atomic weight of barium. Therefore, peaks b, c, and d correspond to $0 \mathrm{Ba}^{2+}-\beta \mathrm{CPP}(1-$ $25), 1 \mathrm{Ba}^{2+}-\beta \mathrm{CPP}(1-25), 2 \mathrm{Ba}^{2+}-\beta \mathrm{CPP}(1-25)$ versions of the peptide.

The bovine $\beta$-CN contains 2 different tryptic phosphopeptides. One of the phosphopeptides has a single phosphorylated serine in the region 33-48 (mono-phosphopeptide FQEEEQQQTEDELQDK) whereas the other contains 4 phosphorylated serines in the region 1-25 (tetra-phosphopeptide or $\beta \mathrm{CPP}$ ). Previous work on elution of phosphopeptides using RP-HPLC has showed that smaller phosphopeptides $(<18$ AA) can elute very early and may even appear in the void volume (Campbell and Morrice, 2002; Kim et al., 2007). This is the direct consequence of phosphorylation, which makes the peptide backbone very hydrophilic. Although the possibility of the monophosphopeptide $(33-48 ; 1,974 \mathrm{~m} / z)$ contamination does exist, it is improbable, as ESI-MS spectrum does not show any peaks below $2,900 \mathrm{~m} / z$.

\section{CONCLUSIONS}

Two modifications made to existing $\beta \mathrm{CPP}$ extraction and purification methods - trypsin digestion time and acetone protein precipitation - resulted in an increase in yield from $14.5 \pm 0.5$ to $32.3 \pm 5.4 \%$. The isolate identified via HPLC was a single peak with ESI-MS confirming 2 forms of the peptide: fragments 1-25 $(87 \%)$ and $2-25(13 \%)$, both from the $\mathrm{N}$ terminus of $\beta-\mathrm{CN}$. Further studies will focus on characterization of $\beta C P P$ structure and its ability to enhance mineral bioavailability in intestinal cells.

\section{ACKNOWLEDGMENTS}

The authors acknowledge the funding support of the Dairy Farmers of Canada, the Natural Sciences and Engineering Research Council of Canada (Ottawa, ON, Canada), the Advanced Foods and Materials Network (Guelph, ON, Canada), and Ryerson University (Toronto, ON, Canada). The authors thank colleagues and scientists at Ryerson University: Kaushiga Pirabaharan, Carolina Silvestre, Christopher Helmeste, Rob Denning, and Jaimie Dufresne as well as John Marshall for their valuable contributions and insights. We also sincerely thank Martin Stillman for helping with our mass spectrometry experiments at Western University (London, ON, Canada).

\section{REFERENCES}

Arakawa, T., and S. N. Timasheff. 1985. Theory of protein solubility. Methods Enzymol. 114:49-77.

Benore-Parsons, M., N. G. Seidah, and L. P. Wennogle. 1989. Substrate phosphorylation can inhibit proteolysis by trypsin-like enzymes. Arch. Biochem. Biophys. 272:274-280.

Boutrou, R., E. Coirre, J. Jardin, and J. Leonil. 2010. Phosphorylation and coordination bond of mineral inhibit the hydrolysis of the beta-casein (1-25) peptide by intestinal brush-border membrane enzymes. J. Agric. Food Chem. 58:7955-7961.

Campbell, D. G., and N. A. Morrice. 2002. Identification of protein phosphorylation sites by a combination of mass spectrometry and solid phase Edman sequencing. J. Biomol. Tech. 13:119-130.

Cosentino, S., B. M. Donida, E. Marasco, E. Del Favero, L. Cantu, G. Lombardi, A. Colombini, S. Iametti, S. Valaperta, A. Fiorilli, G. Tettamanti, and A. Ferraretto. 2010. Calcium ions enclosed in casein phosphopeptide aggregates are directly involved in the mineral uptake by differentiated HT-29 cells. Int. Dairy J. 20:770-776.

Cross, K. J., N. L. Huq, J. E. Palamara, J. W. Perich, and E. C. Reynolds. 2005. Physicochemical characterization of casein phosphopeptide-amorphous calcium phosphate nanocomplexes. J. Biol. Chem. 280:15362-15369.

Cross, K. J., N. L. Huq, and E. C. Reynolds. 2007. Casein phosphopeptides in oral health - Chemistry and clinical applications. Curr. Pharm. Des. 13:793-800.

Farrell, H. M., P. X. Qi, E. D. Wickham, and J. J. Unruh. 2002. Secondary structural studies of bovine caseins: Structure and temperature dependence of beta-casein phosphopeptide (1-25) as analyzed by circular dichroism, FTIR spectroscopy, and analytical ultracentrifugation. J. Protein Chem. 21:307-321.

Holt, C., N. M. Wahlgren, and T. Drakenberg. 1996. Ability of a betacasein phosphopeptide to modulate the precipitation of calcium phosphate by forming amorphous dicalcium phosphate nanoclusters. Biochem. J. 314:1035-1039.

Kim, J., K. Petritis, W. Shen, D. G. Camp II, R. J. Moore, and R. D. Smith. 2007. Phosphopeptide elution times in reversed-phase liquid chromatography. J. Chromatogr. A 1172:9-18. 
Little, E. M., and C. Holt. 2004. An equilibrium thermodynamic model of the sequestration of calcium phosphate by casein phosphopeptides. Eur. Biophys. J. 33:435-447.

Manson, W., and W. D. Annan. 1971. Structure of a phosphopeptide derived from beta-casein. Arch. Biochem. Biophys. 145:16-26.

Pertzoff, V. A. 1933. The solubility of glutamic acid in water and certain organic solvents. J. Biol. Chem. 100:97-104.

Peterson, R. F., L. W. Nauman, and T. L. McMeekin. 1958. The separation and amino acid composition of a pure phosphopeptone prepared from $\beta$-casein by the action of trypsin. Arch. Biochem. Biophys. 80:95-99.

Post, A. E., M. Ebert, and J. Hinrichs. 2009. Beta-casein as a bioactive precursor-Processing for purification. Aust. J. Dairy Technol. 64:84-88.
Rawlings, N. D., and A. J. Barrett. 1994. Families of serine peptidases. Methods Enzymol. 244:19-61.

Reynolds, E. C., P. F. Riley, and N. J. Adamson. 1994. A selective precipitation purification procedure for multiple phosphoserylcontaining peptides and methods for their identification. Anal. Biochem. 217:277-284.

Smyth, E., R. A. Clegg, and C. Holt. 2004. A biological perspective on the structure and function of caseins and casein micelles. Int. J. Dairy Technol. 57:121-126.

Tan, P. S. T., T. Vankessel, F. L. M. Vandeveerdonk, P. F. Zuurendonk, A. P. Bruins, and W. N. Konings. 1993. Degradation and debittering of a tryptic digest from beta-casein by aminopeptidase$\mathrm{N}$ from Lactococcus lactis subsp cremoris WG2. Appl. Environ. Microbiol. 59:1430-1436. 